\title{
Depletion of mitochondrial DNA up-regulates the expression of MDR1 gene via an increase in mRNA stability
}

\author{
Wan Lee ${ }^{1}$, Hyo-Im Choi ${ }^{1}$, \\ Mi-Jin Kim ${ }^{1}$ and Seung-Yoon Park ${ }^{1,2}$ \\ ${ }^{1}$ Department of Biochemistry \\ School of Medicine, Dongguk University \\ Gyeongju 780-714, Korea \\ ${ }^{2}$ Corresponding author: Tel, 82-54-770-2421; \\ Fax, 82-54-770-2447; E-mail, psyoon@ dongguk.ac.kr
}

Accepted 27 December 2007

Abbreviations: COX, cytochrome c oxidase; $\mathrm{EtBr}$, ethidium bromide; MDR, multidrug resistance; mtDNA, mitochondrial DNA

\begin{abstract}
The mutation and reduction of mitochondrial DNA (mtDNA) have been suggested as factors in the carcinogenesis. However, whether the depletion of mtDNA induces multidrug resistance in cancer cells has not been fully investigated. To elucidate the association of cellular mtDNA content and drug resistance, we generated HCT-8 colon cancer cells which revealed a marked decrease in cellular mtDNA and ATP content, concomitant with a lack of mRNAs encoded by mtDNA. The mtDNA-depleted cells showed a decreased sensitivity and accumulation of anti-cancer drugs, suggesting that mtDNA depletion could develop multidrug resistance (MDR) phenotype in HCT-8 cells. We found that the expression level of MDR1 mRNA and its translated product P-glycoprotein was increased in the mtDNA- depleted cells, indicating that the decrease of sensitivity and accumulation of anti-cancer drug in the mtDNA-depleted cells might be due to a substantial increase in the expression of P-glycoprotein. Furthermore, increased expression of MDR1 mRNA and P-glycoprotein was due to an increase of mRNA stability rather than transcriptional activation. Taken together, these results indicate that mtDNA depletion can induce an increased P-glycoprotein expression via an increase of mRNA stability and suggest that the mtDNA depletion in cancer cells plays an important role in the induction of MDR phenotype.
\end{abstract}

Keywords: colonic neoplasms; DNA, mitochondrial; drug resistance; P-glycoprotein; RNA stability

\section{Introduction}

It has been reported that long-term treatment of cells with low doses $(0.1-2 \mu \mathrm{g} / \mathrm{ml})$ of ethidium bromide (EtBr), an inhibitor of DNA/RNA synthesis, specifically suppresses the replication and transcription of extrachromosomal genetic components such as mtDNA without affecting nuclear DNA replication and transcription (Zylber et al., 1969; Desjardins et al., 1985; Hayakawa et al., 1998). Therefore, mtDNA-depleted cells have been important tools in the investigation of the cellular components regulated by mtDNA (King and Attardi, 1989). The role of mitochondrial dysfunction in tumorigenesis has been investigated extensively using multiple approaches (Shay and Werbin, 1987; Cavalli and Liang, 1998). Previous studies have reported that a wide rage of tumors exhibit mtDNA abnormality such as point mutations and deletions (Horton et al., 1996; Polyak et al., 1998; Fliss et al., 2000; Yeh et al., 2000). Although it is not clear whether mtDNA abnormalities are direct contributing factor or indirect effect of cancer development because the genes involved in tumorigenicity are largerly nuclear encoded, recent studies showed that mitochondria-to-nucleus stress signaling induces tumor progression and cell invasion (Amuthan et al., 2001, 2002).

The development of multidrug resistance (MDR) phenotype is a major impediment to cancer chemotherapy for many malignancies (Gottesman et al., 2002). One of major mechanisms of drug resistance in cancer cells is overexpression of P-glycoprotein that is encoded by the MDR1 gene (Ivy et al., 1996; Borst, 1997). P-glycoprotein is a 170-kDa transmembrane protein that belongs to the ATPbinding cassette $(A B C)$ transporter superfamily (Juliano and Ling, 1976). P-glycoprotein functions as an energy-dependent efflux pump that reduces the intracellular concentration of cytotoxic compounds and thus confers resistance to unrelated drugs that differ widely with respect to molecular structure and target specificity such as paclitaxel, vincristine, and doxorubicin (Gottesman et al., 2002). Recently, several lines of evidence obtained from mtDNA-depleted cells have revealed that mitochondrial stress resulting from the reduction of mtDNA causes substantial resistance of apoptosis (Park et al., 2004; Biswas et al., 2005), suggesting that the depletion of mtDNA could induce resist- 
ance for cancer chemotherapy. However, it is not clear whether the mtDNA-depletion is a contributing factor in the expression of molecules responsible for drug resistance.

In this study, we provide evidence that the depletion of mtDNA induces MDR phenotype in HCT-8 colon cancer cells. Furthermore, we show that this is due to an increase in mRNA stability.

\section{Materials and Methods}

\section{Reagents and antibodies}

Doxorubicin was purchased from Sigma (St. Louis, Mo). $\left[{ }^{3} \mathrm{H}\right]$-paclitaxel was obtained from Moravek Biochemicals (Labrea, CA). Monoclonal antibody directed against P-glycoprotein was purchased from Calbiochem. Polyclonal antibody directed against actin was obtained from Sigma. HRP-conjugated anti-mouse $\lg G$ and anti-rabbit $\lg G$ were obtained from Santa Cruz (Santa Cruz, CA). Oligonucleotides primers were from Bionics (Seoul, Korea). All biochemicals were of analytical grade and were purchased from commercial suppliers.

\section{Cells culture}

HCT-8 human colon cancer cells were grown in RPMI-1640 medium supplemented with $10 \%$ (v/v) FBS (Invitrogen, Grand Island, NY), penicillin (100 $\mathrm{IU} / \mathrm{ml})$ and streptomycin $(100 \mu \mathrm{g} / \mathrm{ml})$. Depletion of
mtDNA was induced by treatment with ethidium bromide $(0.2 \mu \mathrm{g} / \mathrm{ml})$ for $2-3$ weeks. The cell lines exhibiting reduced mtDNA content were grown in the presence of $1 \mathrm{mM}$ sodium pyruvate (Sigma) and $50 \mu \mathrm{g} / \mathrm{ml}$ uridine (Sigma). The control HCT-8 cells were maintained for the same time period under normal culture condition.

\section{Measurement of cellular ATP levels}

Cellular ATP levels were measured using a Somatic cell ATP assay kit (Sigma) as previously described (Biswas et al., 1999), which is based on the assay of ATP-driven luciferin luciferase activity. Briefly, cells were lysed with an ATP releasing reagent (Sigma), and the lysates were assayed for luciferase activity in accordance with the manufacturer's instructions. ATP-dependent formation of light was measured in a Luminometer (Lumat LB 9501) with appropriate ATP standards.

\section{Total DNA extraction and PCR}

Total cellular DNA was extracted using a DNeasy Tissue kit in accordance with the manufacturer's instructions (Qiagen, Hilden, Germany). The amplification of mtDNA was performed under the following conditions: $94^{\circ} \mathrm{C}$ for $2 \mathrm{~min}$ (initial denaturation); $94^{\circ} \mathrm{C}$ for $30 \mathrm{~s}, 60^{\circ} \mathrm{C}$ for $30 \mathrm{~s}, 72^{\circ} \mathrm{C}$ for $45 \mathrm{~s}$ (25 cycles); and $72^{\circ} \mathrm{C}$ for $10 \mathrm{~min}$ (final extension). The primers used in this study are shown in Table 1.

Table 1. DNA sequences of primers used for genomic DNA PCR and real-time PCR.

\begin{tabular}{|c|c|c|c|}
\hline \multirow{2}{*}{ Identity } & \multirow{2}{*}{ Nucleotide sequences } & \multicolumn{2}{|c|}{ Product size } \\
\hline & & gDNA & mRNA \\
\hline COX-I & $\begin{array}{l}\text { Forward: 5'-CCTGACTGGCATTGTATTAG-3' } \\
\text { Reverse: 5'-GATAGGATGTTTCATGTGGTG-3' }\end{array}$ & 306 & 306 \\
\hline COX-II & $\begin{array}{l}\text { Forward: 5'-CATCCCTACGCATCCTTTAC-3' } \\
\text { Reverse: 5'-GGTTTGCTCCACAGATTTCAG-3' }\end{array}$ & 375 & 375 \\
\hline COX-IV & $\begin{array}{l}\text { Forward: 5'-CAGAAGGCACTGAAGGAGAAG-3' } \\
\text { Reverse: 5'-TCATGTCCAGCATCCTCTTG-3' }\end{array}$ & $\mathrm{N} / \mathrm{A}$ & 271 \\
\hline MDR1 & $\begin{array}{l}\text { Forward: 5'-GGAGTGTCCGTGGATCACAAG-3' } \\
\text { Reverse: 5'-AATACATCATTGCCTGGGTGAAG-3' }\end{array}$ & $\mathrm{N} / \mathrm{A}$ & 843 \\
\hline GAPDH & $\begin{array}{l}\text { Forward: 5'-TGCCACCCAGAAGACTGTG-3' } \\
\text { Reverse: 5'-ATGTAGGCCATGAGGTCCAC-3' }\end{array}$ & 446 & 446 \\
\hline$\beta$-actin & $\begin{array}{l}\text { Forward: 5'-TCACCCACACTGTGCCCATCTACGA-3' } \\
\text { Reverse: 5'-GGATGCCACAGGATTCCATACCCA-3' }\end{array}$ & N/A & 348 \\
\hline
\end{tabular}




\section{RNA extraction and RT-PCR}

Total RNA was extracted from cells using Trizol reagent in accordance with the manufacturer's instructions (Invitrogen), and the quantity and quality of the isolated RNA was then determined by measuring the absorbance at 260 and $280 \mathrm{~nm}$. The reverse transcription reaction was performed in a reaction mixture comprised of $2 \mu \mathrm{g}$ of total RNA, $200 \mathrm{ng}$ of oligo $(\mathrm{dT})_{15}$ primer, $1 \times$ reverse transcription buffer, $0.5 \mathrm{mM}$ deoxynucleotide triphosphate mixture, RNasin recombinant ribonuclease inhibitor (Promega, Madison, WI), and $200 \mathrm{U}$ of M-MLV reverse transcriptase (Promega). After incubation for $50 \mathrm{~min}$ at $42^{\circ} \mathrm{C}$, the reverse transcription reaction was terminated by heating it for 15 min at $70^{\circ} \mathrm{C}$. The newly synthesized cDNA was then amplified by PCR in a reaction mixture comprised of $2 \mu \mathrm{l}$ of cDNA template, $1.5 \mathrm{mM} \mathrm{MgCl}, 1$ $\mathrm{U}$ of Tag polymerase, and $0.3 \mu \mathrm{M}$ of primers. The amplification was performed under the following conditions: $94^{\circ} \mathrm{C}$ for $2 \mathrm{~min}$ (initial denaturation); $94^{\circ} \mathrm{C}$ for $30 \mathrm{~s}, 58^{\circ} \mathrm{C}$ for $30 \mathrm{~s}, 72^{\circ} \mathrm{C}$ for $60 \mathrm{~s}(30$ cycles); and $72^{\circ} \mathrm{C}$ for $7 \mathrm{~min}$ (final extension). PCR products were electrophoresed on $2 \%$ agarose gels, and then visualized by ethidium bromide staining. Band intensities were quantitated by densitometric scanning using an analytical scanning system (Alphalmager 1220) and normalized to GAPDH expression levels.

\section{Quantitative gene expression analysis}

In order to confirm gene expression levels, quantitative real time RT-PCR (qRT-PCR) was carried out in Rotor Gene 2000 (Corbett Research, Mortlake, Australia) using a SYBR-Green PCR Master Mix in accordance with the manufacturer's instructions (Qiagen, Valencia, CA). All of the gene-specific primer sets used for qRT-PCR are listed in Table I. After amplification, the authenticity of the PCR products was verified by melting curve analysis and agarose gel electrophoresis. Images from electrophoresed gels were captured by a camera in a computer-assisted imaging system (Alphalmager 1220). The qRT-PCR results were analyzed using Rotor-Gene analysis software version 6.0 (Corbett Research). The comparative cycle threshold $\left(C_{T}\right)$ method was used to analyze the data by generating relative values of the amount of target cDNA. Relative quantitation for any given gene, expressed as percentage variation over control, was calculated after determination of the difference between $C_{T}$ of the given gene $A$ and that of the calibrator gene $B$ ( $\beta$-actin) in the depleted cells $\left(\Delta C_{T 1}=\Delta C_{T 1 A}-\Delta C_{T B}\right)$ and control cells $\left(\Delta C_{T 0}=\right.$ $\left.\Delta C_{\text {TOA }}-\Delta C_{T B}\right)$ using the $2^{-\Delta \Delta C T(1-0)}$ formula. $C_{T}$ values are means of triplicate measurements.

\section{Cell proliferation assay}

Cell viability was assessed using a CellTiter 96 Aqueous One Solution cell proliferation assay kit (Promega), as previously described (Ahn et al., 2006). Briefly, $1.0 \times 10^{3}$ cells per well were seeded in 96-well plates to which were added a dilution series of doxorubicin and vincristine in triplicate and incubated under standard culture conditions. After 4 days, a volume of $20 \mu \mathrm{l}$ of the detection solution were added to each well and incubated for $90 \mathrm{~min}$ at $37^{\circ} \mathrm{C}$ prior to measuring absorbance at $490 \mathrm{~nm}$ using a microplate reader (Biorad).

\section{Paclitaxel accumulation}

Steady-state paclitaxel accumulation was conducted as previously described (Wu et al., 2003). In brief, parent HCT-15 cells and transfectants were seeded in 6-well plates and grown for $48 \mathrm{~h}$. Then, the growth medium was aspirated and replaced with 1 $\mathrm{ml}$ of RPMI 1640 containing $50 \mathrm{nM}$ of $\left[^{3} \mathrm{H}\right]-$ paclitaxel (10.0 Ci/mmol; Moravek Biochemicals). After incubation for $2 \mathrm{~h}$ at $37^{\circ} \mathrm{C}$, the cells were cooled on ice, washed three times with ice-cold PBS, and solubilized with $0.2 \mathrm{ml}$ of $1 \%$ SDS. The radioactivity in each sample was determined by scintillation counting.

\section{Gel electrophoresis and immunoblotting}

Equal amount $(20 \mu \mathrm{g})$ of total cell lysates were subjected to SDS-PAGE on 7 or $10 \%$ resolving gels as previously described (Park et al., 2005). Separated proteins were electrophoretically transferred to nitrocellulose membrane (Bio-Rad), blocked with $5 \%$ skim milk in Tris-buffered saline (TBS), and then incubated overnight at $4^{\circ} \mathrm{C}$ with antibody directed against $\mathrm{P}$-glycoprotein or actin in TBS-T (Tris-buffered saline plus $0.1 \%$ Tween 20) containing $1 \%$ skim milk. After washes with TBS-T, the membranes were incubated with HRP-conjugated anti-mouse or anti-rabbit IgG. Immunoreactive bands were visualized using an enhanced chemiluminescence (ECL) kit (Amersham, Little Chalfont, Buckinghamshire, UK).

\section{Dual luciferase reporter assay}

Control and mtDNA-depleted HCT-8 cells in 6-well plate were cotransfected with $\mathrm{pGL} 3 /$ basic or pMDR1-luc vector together with pRL-SV40 for constitutive expression of Renilla luciferase as an internal control. Luciferase activity was measured 
$48 \mathrm{~h}$ after transfection using a Dual Luciferase assay kit in accordance with the manufacturer's instructions (Promega). The ratio of firefly luciferase activity to Renilla luciferase activity was presented in arbitrary units as the relative luciferase activities.

\section{mRNA stability assay}

Control and mtDNA-depleted HCT-8 cells were incubated with $12.5 \mu \mathrm{g} / \mathrm{ml}$ actinomycin $D$ to inhibit transcription. The cells were harvested at six different time points after actinomycin addition, and total RNA was isolated as described above. The level of MDR1 transcript was analyzed by RT-PCR and real-time PCR.

\section{Statistical analysis}

The statistical significance was assessed by the T-test. A $P<0.05$ was considered to be statistically significant.
A

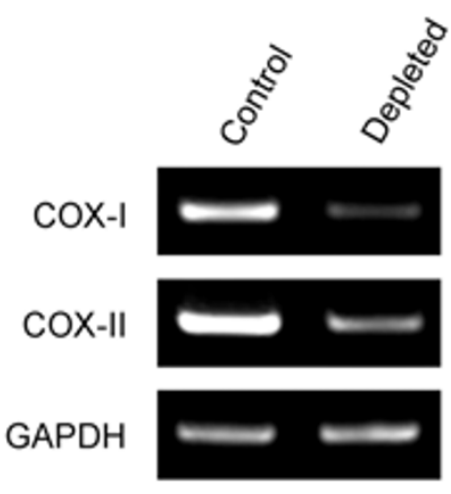

C

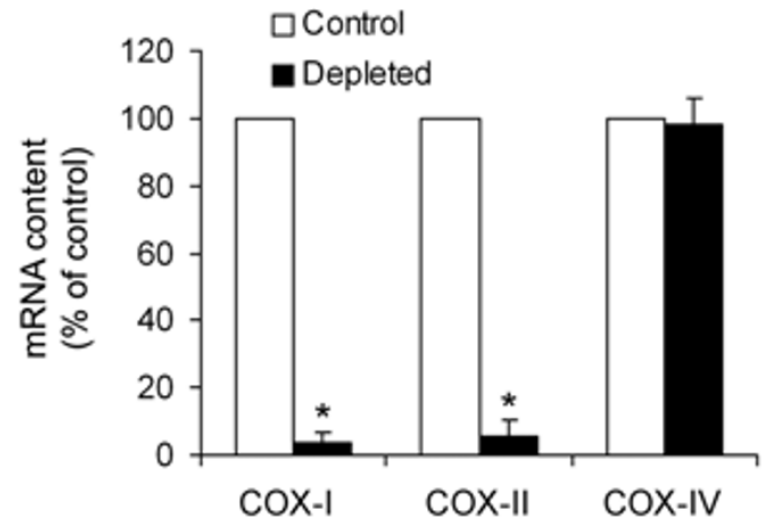

B

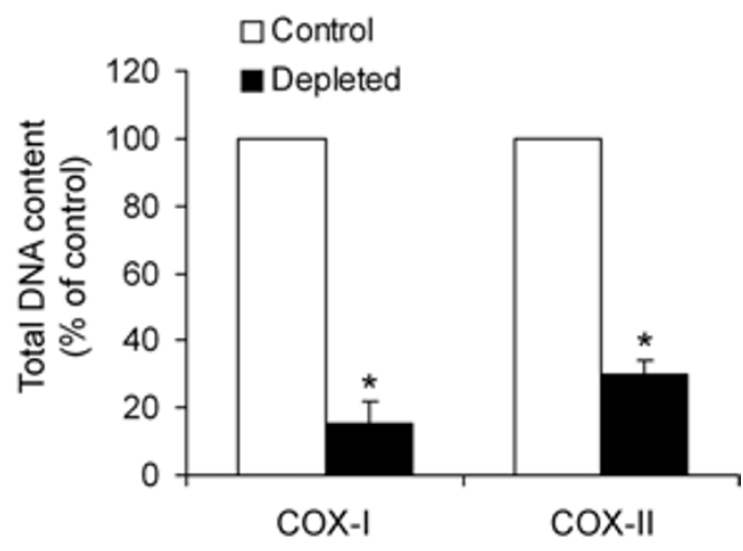

$\mathrm{D}$

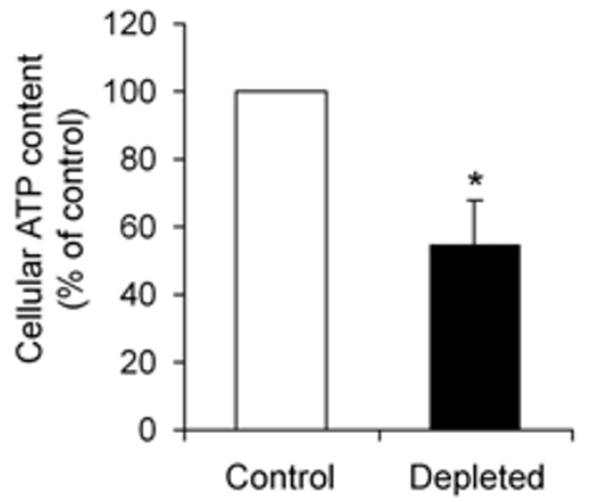

Figure 1. Characterization of mtDNA-depleted HCT-8 cells. (A) Genomic DNA content. Genomic DNA was isolated from control and mtDNA-depleted HCT-8 cells, and mtDNA-encoded genes including cytochrome $c$ oxidase subunit I (COX-I) and cytochrome c oxidase subunit II (COX-II) were amplified by PCR. GAPDH is used as a nuclear DNA-encoded control. The PCR products were electrophoresed on $2 \%$ agarose gel and then visualized by EtBr staining. A representative result of three independent experiments is shown. (B) The PCR products were quantified by densitometry, normalized to GAPDH expression, and expressed as a percentage relative to that obtained in control HCT-8 cells. The results are expressed as the means \pm SD of three independent experiments. T-test: ${ }^{*} P<0.01$. (C) RT-PCR analysis of mRNAs transcribed from mtDNA and nuclear DNA. Total RNA was extracted from control and mtDNA-depleted HCT-8 cells, and mtDNA-encoded transcripts such as COX-I and COX-II, and nuclear DNA-encoded transcripts such as COX-IV were analyzed by real-time PCR. The mRNA levels were expressed as a percentage relative to that obtained in control HCT-8 cells. The results are expressed as the means $\pm S D$ of three independent experiments. T-test: ${ }^{*} P<0.01$. (D) Cellular ATP content. Total cellular ATP levels were measured using a somatic cell ATP assay kit as described in Materials and Methods. ATP content was expressed as a percentage relative to that observed in control HCT-8 cells. The results are expressed as the means \pm SD of three independent experiments. T-test: ${ }^{*} P<0.05$. 


\section{Results}

\section{Establishment of mtDNA-depleted HCT-8 cells}

To develop partially mtDNA-depleted cell lines, we exposed HCT-8 cells to $\mathrm{EtBr}(0.2 \mu \mathrm{g} / \mathrm{ml})$ in RPMI1640 medium supplemented with pyruvate and uridine, which are shown to be essential for the growth of mtDNA-depleted cells (King and Attardi, 1989). The mtDNA content from HCT-8 cells cultured with or without $\mathrm{EtBr}$ was monitored routinely by amplifying total DNA. As shown in Figures $1 \mathrm{~A}$ and $\mathrm{B}$, cytochrome oxidase subunits I (COX I) and II (COX II) which are encoded only in mtDNA were hardly amplified from the total DNA of the cells treated with EtBr. In contrast, nuclear DNAencoded GAPDH was equally detected in both control and EtBr-treated cells (Figure $1 \mathrm{~A}$ ), indicating that prolonged treatment with $\mathrm{EtBr}$ selectively depleted mtDNA without altering the nuclear DNA replication in HCT-8 cells. Under these experimental conditions, mtDNA was depleted to $<30 \%$ of normal cells after 3 week of growth in

A

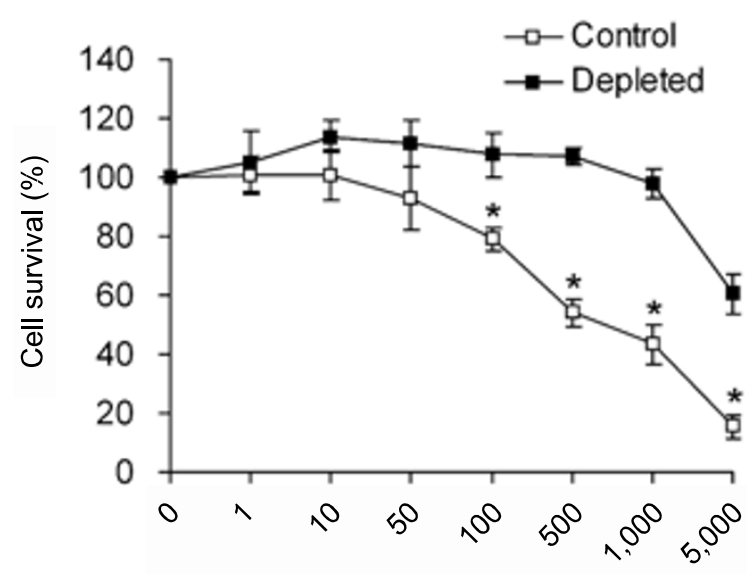

Doxorubicin (nM)

B

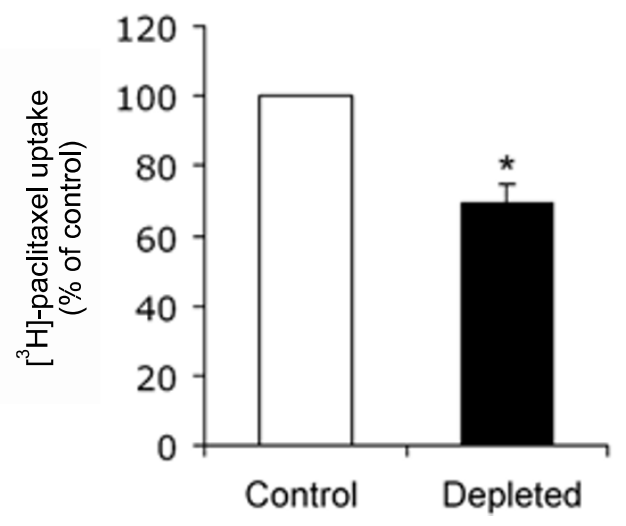

the presence of EtBr. We next analyzed the differential expressions of mitochondrial and nuclear genes such as COX I, II, and IV in the control and mtDNA-depleted cells. mRNA contents of COX I and COX II, which are mtDNA-encoded genes were significantly reduced in the depleted cells, whereas mRNA content of COX IV, which are encoded by nuclear DNA, were not changed in the depleted cells (Figure $1 \mathrm{C}$ ), suggesting that mitochondrial mRNA levels correlates with the cellular mtDNA contents in these cells. In addition, the depleted cells showed a substantial decrease in total cellular ATP when compared with control cells (Figure 1D).

\section{MDR1 mRNA and P-glycoprotein are up-regulated in mtDNA-depleted cells}

To demonstrate whether the depletion of mtDNA content in HCT-8 cells induces drug resistance, we measured the sensitivity of anti-cancer drug in the control and mtDNA-depleted cells using a cell

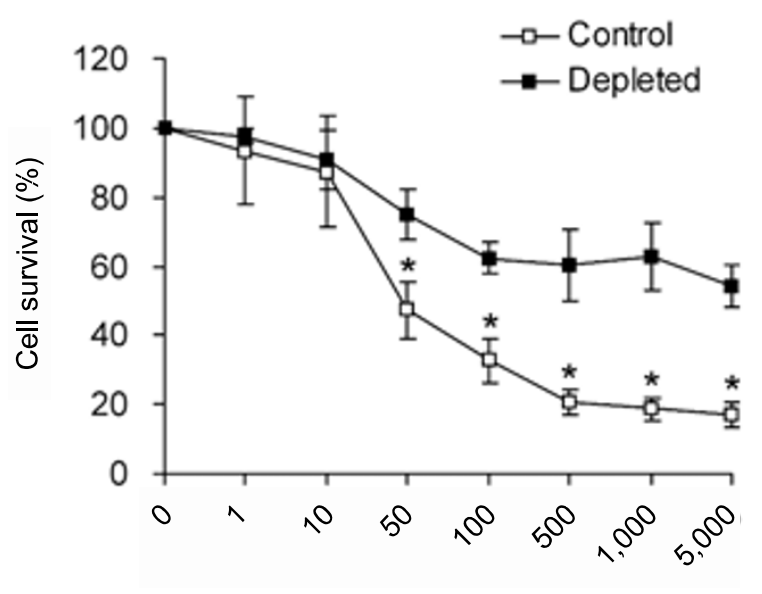

Vincristine (nM)

Figure 2. The sensitivity to doxorubicin and the accumulation of paclitaxel. (A) $1.0 \times 10^{3}$ cells per well were seeded in 96-well plate to which were added a dilution series of doxorubicin (left panel) and vincristine (right panel) in triplicate and incubated for 4 days under standard culture conditions. Cell viability was assessed using a CellTiter 96 Aqueous One Solution cell proliferation assay kit (Promega). Results are expressed as means $\pm S D$ of three independent experiments. T-test: ${ }^{*} P<0.05$. (B) Control and mtDNA-depleted HCT-8 cells were seeded in 6-well plates and grown for $48 \mathrm{~h}$. The cells were then incubated with $50 \mathrm{nM}\left[^{3} \mathrm{H}\right]$-paclitaxel for $2 \mathrm{~h}$ at $37^{\circ} \mathrm{C}$. At the end of incubation, the cells were cooled on ice, washed three times with ice-cold PBS, and solubilized with $0.2 \mathrm{ml}$ of $1 \%$ SDS. The radioactivity in each sample was determined by scintillation counting. The Results are expressed as the means \pm SD of three independent experiments. T-test: ${ }^{*} P<0.05$. 
A

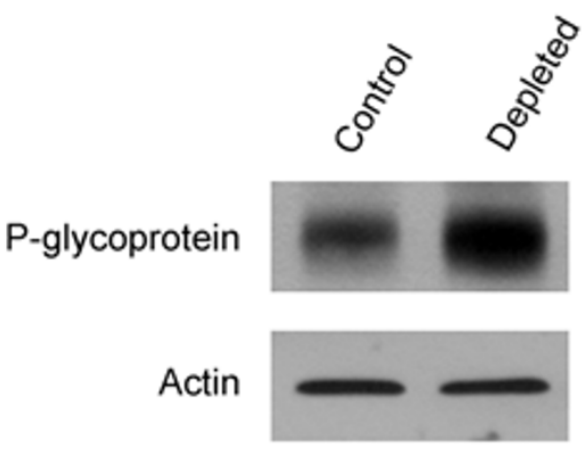

B

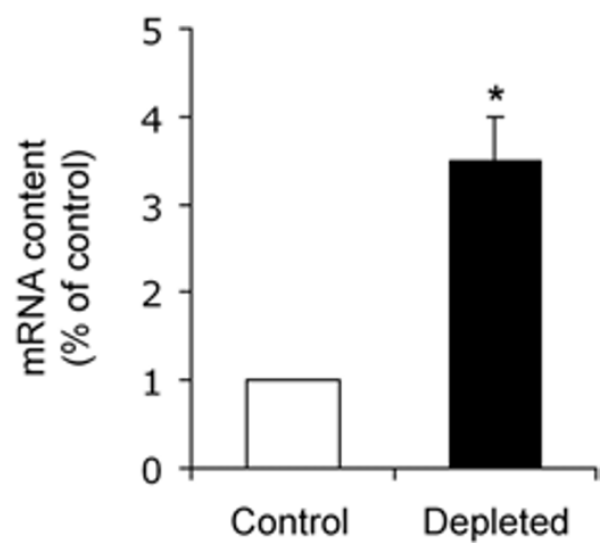

Figure 3. Expression of MDR1 mRNA and P-glycoprotein in control and mtDNA-depleted HCT-8 cells. (A) Cell lysates were prepared from control and mtDNA-depleted HCT-8 cells. Equal amounts ( $20 \mu \mathrm{g}$ proteins) of cell lysates were separated via $7 \%$ SDS-PAGE and subjected to immunoblotting with anti-P-glycoprotein or anti-actin antibody. A representative result of three independent experiments is shown. (B) Total RNA was isolated from control and mtDNA-depleted HCT-8 cells, and the level of MDR1 transcript was analyzed by real-time PCR. The relative values were expressed as fold increase relative to that observed in control HCT-8 cells. The Results are expressed as the means \pm SD of three independent experiments. T-test: ${ }^{*} P<0.01$.

proliferation assay. The sensitivity to doxorubicin and vincristine, P-glycoprotein-transportable compounds, is reduced in the mtDNA-depleted cells when compared with that observed in control cells (Figure 2A). We next investigated intracellular drug accumulation in mtDNA-depleted cells. As shown in Figure 2B, the uptake of paclitaxel is decreased by approximately $70 \%$ in the mtDNA-depleted cells when compared with control cells. Therefore, these results indicate that mtDNA depletion provokes impediment to chemotherapy in HCT-8 cells and suggest that the reduction of mtDNA is associated with MDR phenotype.

To investigate the cellular mechanism involved in the induction of MDR phenotype by mtDNA reduction, we measured the expression level of P-glycoprotein, which is encoded by the MDR1 gene and known to play a key role in drug resistance of cancer cells. Immunoblot analysis showed an increased P-glycoprotein expression in the mtDNA-depleted cells when compared with control cells (Figure 3A). The level of MDR1 mRNA is also significantly increased in mtDNA-depleted HCT-8 cells (Figure $3 B$ ). These results suggest that the decrease of sensitivity and accumulation of anticancer drug in the mtDNA-depleted cells might be due to a substantial increase in stead-state MDR1 mRNA levels.

\section{Up-regulation of MDR1 is mediated by the increase of mRNA stability}

To determine whether MDR1 mRNA up-regulation was due to transcriptional activation, we performed

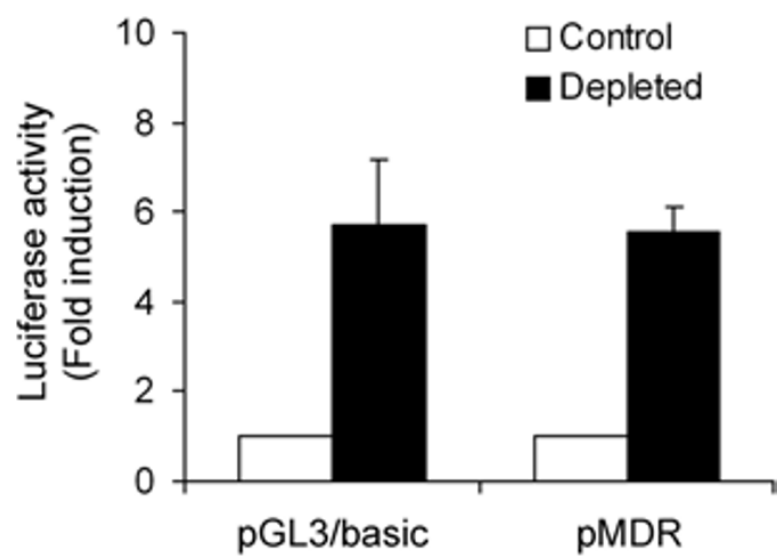

Figure 4. Analysis of MDR1 promoter activity in control and mtDNA-depleted HCT-8 cells. Promoter activity of a luciferase reporter gene driven by the MDR1 promoter was measured after transfection of control and mtDNA-depleted cells with pMDR1. Luciferase activity was normalized to Renilla luciferase activity, and shown as fold increase of luciferase activity over the value obtained from the empty pGL3 reporter vector alone. The Results are expressed as the means \pm SD of three independent experiments.

a gene reporter assay in which an MDR1 promoter fragment was placed upstream of the luciferase reporter gene. However, promoter activity was equivalent in both control and mtDNA-depleted cells (Figure 4), indicating that the depletion of mtDNA did not upregulate the activity of MDR1 promoter. Since the increase of steady-state MDR1 mRNA was not due to transcriptional activation, we investigated whether change in the rates of mRNA decay might be involved. To determine the half- 


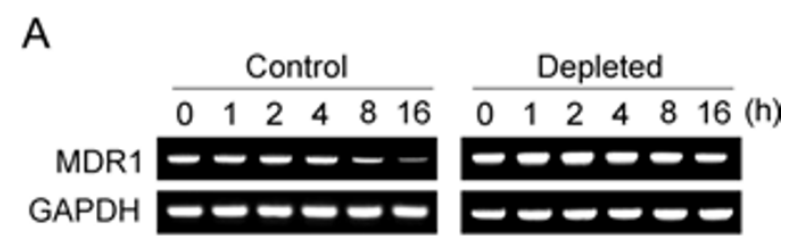

$\mathrm{B}$

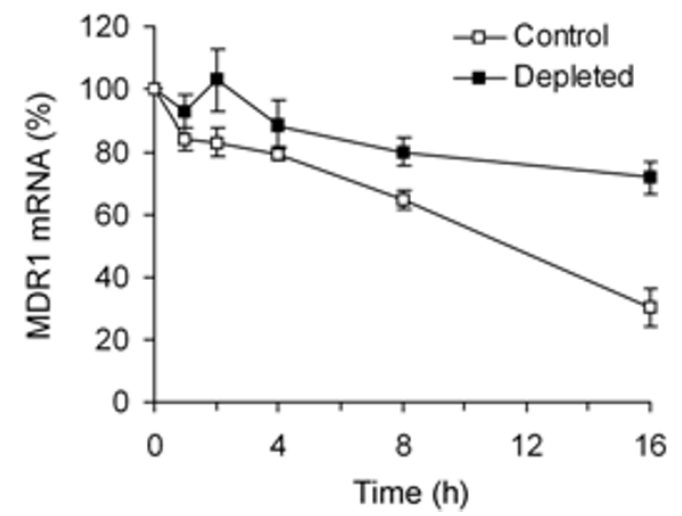

Figure 5. Stability of MDR1 mRNA in control and mtDNA-depleted HCT-8 cells. (A) Control and mtDNA-depleted HCT-8 cells were treated with $12.5 \mu \mathrm{g} / \mathrm{ml}$ actinomycin $\mathrm{D}$ for various times, followed by extraction and analysis of RNA via RT-PCR. GAPDH is used as an internal control. A representative result of three independent experiments is shown. (B) The level of MDR1 transcript was analyzed by real-time PCR. The level of MDR1 mRNA was expressed as a percentage relative to that observed at time 0 . The Results are expressed as the means $\pm S D$ of three independent experiments.

lives of MDR1 mRNA in control and mtDNA-depleted HCT-8 cells, we treated cells with actinomycin $D$, which is a transcriptional inhibitor that blocks further incorporation of uridine into RNA and thereby prevents increase of mRNA, and monitored the disappearance of MDR1 mRNA in the presence of actinomycin $D$. The results showed that the half-life of MDR1 mRNA was prolonged from approximately $10 \mathrm{~h}$ in normal HCT-8 cells to greater than $16 \mathrm{~h}$ in the mtDNA-depleted cells (Figure 5). In contrast, the half-life of a long-lived message (GAPDH) was unchanged in both cells. Thus, up-regulation of MDR1 mRNA levels following mtDNA depletion is due to an increase in mRNA stability.

\section{Discussion}

The cellular treatment with low dose EtBr specifically inhibits transcription and replication of circular DNA by deleting RNA primers required for the initiation of replication (Zylber et al., 1969; Desjardins et al., 1985; Hayakawa et al., 1998), and it has been a useful tool for the study of various cellular responses affected by changes in mtDNA contents (Biswas et al., 1999; Amuthan et al., 2001, 2002). Studies using mtDNA-depleted cells to evaluate the role of mtDNA in the expression of MDR1 and P-glycoprotein have yielded mixed results. Pillay and colleagues found that $\mathrm{P}$-glycoprotein is up-regulated in rat hepatoma $\rho 0$ cells (Pillay et al., 1998), whereas Liang and Ullyatt found that mRNA expression of MDR1 and multidrug resistance-associated protein 1 (MRP1/ $A B C C 1)$, putatively associated drug resistance was unchanged in mtDNA-depleted U937 cells (Liang and Ullyatt, 1998). Although Moye-Rowley and colleagues also reported that multiple signals from dysfunctional mitochondria activate the pleiotropic drug resistance pathway in S. cerevisiae (Hallstrom and Moye-Rowley, 2000; Moye-Rowley, 2005), it is not clear whether the mtDNA-depletion is a contributing factor in the expression of molecules responsible for drug resistance. In this study, we generated HCT-8 cells containing partially depleted mtDNA ( $<80 \%$ of control level) by EtBr treatment. The results of our study showed that the depletion of mtDNA led to an increased expression of MDR1 mRNA and P-glycoprotein in HCT-8 colon cancer cells.

Transcriptional activation is generally accepted to be the principle mechanism for up-regulating MDR1 gene expression (Labialle et al., 2002). Several regulatory elements such as Sp1, AP-1, NF-Y, and C/EBP $\beta$, have been characterized. It is reported that MDR1 expression in cancer cells is up-regulated by activation of NF- $\mathrm{B}$ (Kuo et al., 2002; Bentires-Alj et al., 2003). However, recent studies reported that the expression of MDR1 is also regulated by post-transcriptional levels (Yague et al., 2003; Gomez-Martinez et al., 2007). In this study, we found that up-regulation of MDR1 gene in the mtDNA-depleted cells results from an increase in mRNA stability. The cis-determinants involved in mRNA stability is located in the 3'-untranslated region of the transcripts (Wilusz et al., 2001). The MDR1 3' UTR contains several potential AUbinding protein recognition sites that could regulate rapid mRNA decay (Marino et al., 1990). The half-life of MDR1 mRNA in HCT-8 cells is similar to that observed in the human hepatoma cell line HepG2 (Prokipcak et al., 1999), and significantly increased by the depletion of mtDNA. Although our results demonstrated that the depletion of mtDNA induces the up-regulation of MDR1 gene via an increase of mRNA stability, a recent study provided evidence that MDR1 expression is also regulated at translational initiation (Yague et al., 2003). Thus, it remains the possibility that translational regulation is also involved in up-regulation of P-glyco- 
protein in the mtDNA-depleted cells. Further studies are needed for elucidating whether MDR1 expression is regulated at the translational level under mtDNA-depleted conditions.

In this study, we showed that mtDNA-depleted HCT-8 cells are resistant to doxorubicin and vincristine, P-glycoprotein-transportable compounds. Our results indicate that drug resistance is mediated by a decreased accumulation of drug via up-regulation of P-glycoprotein. However, a previous study provided evidence that the depletion of mtDNA induces a resistance on cell death via an adaptive increase in the expression of anti-oxidant enzymes (Park et al., 2004). We found that the expression of catalase is up-regulated in the mtDNA-depleted HCT-8 cells (unpublished data). Furthermore, several investigators have demonstrated that alteration of mtDNA quantity and quality induces mitochondria-to-nucleus stress signaling which changes the expression level of various nuclear-encoded genes, including anti-apoptotic proteins, Bax and bcl-2 (Amuthan et al., 2001, 2002). Therefore, it appears more likely that drug resistance by the depletion of mtDNA may be mediated by a more complicated mechanism that remains to be established.

In summary, our results showed that the depletion of mtDNA increases MDR1 gene expression in HCT-8 colon cancer cells. Furthermore, we demonstrated that up-regulation of MDR1 expression is due to mRNA stabilization. Considering that MDR1 has an important role in drug resistance of cancer cells, our identification would help to elucidate the molecular mechanism by which drug resistance is induced in the mtDNA-depleted cells.

\section{Acknowledgements}

This work was supported by the grant No. RTI04-01-01 from the Regional Technology Innovation Program of the MOCIE, Advanced Medical Technology Cluster for Diagnosis and Prediction at Kyungpook National University from MOCIE and by a grant from Korea Health 21 R\&D Project, Ministry of Health and Welfare, Korea (00-PJ3-PG6-GN070001).

\section{References}

Ahn BH, Min G, Bae YS, Min DS. Phospholipase D is activated and phosphorylated by casein kinase-Il in human U87 astroglioma cells. Exp Mol Med 2006;38:55-62

Amuthan G, Biswas G, Zhang SY, Klein-Szanto A, Vijayasarathy $C$, Avadhani NG. Mitochondria-to-nucleus stress signaling induces phenotypic changes, tumor progression and cell invasion. Embo J 2001;20:1910-20
Amuthan G, Biswas G, Ananadatheerthavarada HK, Vijayasarathy C, Shephard HM, Avadhani NG. Mitochondrial stress-induced calcium signaling, phenotypic changes and invasive behavior in human lung carcinoma A549 cells. Oncogene 2002;21:7839-49

Bentires-Alj M, Barbu V, Fillet M, Chariot A, Relic B, Jacobs N, Gielen J, Merville MP, Bours V. NF-kappaB transcription factor induces drug resistance through MDR1 expression in cancer cells. Oncogene 2003;22:90-7

Biswas G, Adebanjo OA, Freedman BD, Anandatheerthavarada HK, Vijayasarathy C, Zaidi M, Kotlikoff M, Avadhani NG. Retrograde $\mathrm{Ca} 2+$ signaling in $\mathrm{C} 2 \mathrm{C} 12$ skeletal myocytes in response to mitochondrial genetic and metabolic stress: a novel mode of inter-organelle crosstalk. Embo J 1999;18:522-33

Biswas G, Anandatheerthavarada HK, Avadhani NG. Mechanism of mitochondrial stress-induced resistance to apoptosis in mitochondrial DNA-depleted C2C12 myocytes. Cell Death Differ 2005;12:266-78

Borst P. Multidrug resistant proteins. Semin Cancer Biol 1997;8:131-4

Cavalli LR, Liang BC. Mutagenesis, tumorigenicity, and apoptosis: are the mitochondria involved? Mutat Res 1998;398:19-26

Desjardins P, Frost E, Morais R. Ethidium bromide-induced loss of mitochondrial DNA from primary chicken embryo fibroblasts. Mol Cell Biol 1985;5:1163-9

Fliss MS, Usadel H, Caballero OL, Wu L, Buta MR, Eleff SM, Jen J, Sidransky D. Facile detection of mitochondrial DNA mutations in tumors and bodily fluids. Science 2000;287: 2017-9

Gomez-Martinez A, Garcia-Morales P, Carrato A, CastroGalache MD, Soto JL, Carrasco-Garcia E, Garcia-Bautista M, Guaraz P, Ferragut JA, Saceda M. Post-transcriptional regulation of $P$-glycoprotein expression in cancer cell lines. Mol Cancer Res 2007;5:641-53

Gottesman MM, Fojo T, Bates SE. Multidrug resistance in cancer: role of ATP-dependent transporters. Nat Rev Cancer 2002;2:48-58

Hallstrom TC, Moye-Rowley WS. Multiple signals from dysfunctional mitochondria activate the pleiotropic drug resistance pathway in Saccharomyces cerevisiae. J Biol Chem 2000;275:37347-56

Hayakawa T, Noda M, Yasuda K, Yorifuji H, Taniguchi S, Miwa I, Sakura H, Terauchi Y, Hayashi J, Sharp GW, Kanazawa Y, Akanuma Y, Yazaki Y, Kadowaki T. Ethidium bromideinduced inhibition of mitochondrial gene transcription suppresses glucose-stimulated insulin release in the mouse pancreatic beta-cell line betaHC9. J Biol Chem 1998;273: 20300-7

Horton TM, Petros JA, Heddi A, Shoffner J, Kaufman AE, Graham SD Jr, Gramlich T, Wallace DC. Novel mitochondrial DNA deletion found in a renal cell carcinoma. Genes Chromosomes Cancer 1996;15:95-101

Ivy SP, Olshefski RS, Taylor BJ, Patel KM, Reaman GH. Correlation of $\mathrm{P}$-glycoprotein expression and function in 
childhood acute leukemia: a children's cancer group study. Blood 1996;88:309-18

Juliano RL, Ling V. A surface glycoprotein modulating drug permeability in Chinese hamster ovary cell mutants. Biochim Biophys Acta 1976;455:152-62

King MP, Attardi G. Human cells lacking mtDNA: repopulation with exogenous mitochondria by complementation. Science 1989;246:500-3

Kuo MT, Liu Z, Wei Y, Lin-Lee YC, Tatebe S, Mills GB, Unate $\mathrm{H}$. Induction of human MDR1 gene expression by 2-acetylaminofluorene is mediated by effectors of the phosphoinositide 3-kinase pathway that activate NF-kappaB signaling. Oncogene 2002;21:1945-54

Labialle S, Gayet L, Marthinet E, Rigal D, Baggetto LG. Transcriptional regulators of the human multidrug resistance 1 gene: recent views. Biochem Pharmacol 2002;64:943-8

Liang BC, Ullyatt E. Increased sensitivity to cis-diamminedichloroplatinum induced apoptosis with mitochondrial DNA depletion. Cell Death Differ 1998;5:694-701

Marino PA, Gottesman MM, Pastan I. Regulation of the multidrug resistance gene in regenerating rat liver. Cell Growth Differ 1990;1:57-62

Moye-Rowley WS. Retrograde regulation of multidrug resistance in Saccharomyces cerevisiae. Gene 2005;354: 15-21

Park SY, Chang I, Kim JY, Kang SW, Park SH, Singh K, Lee MS. Resistance of mitochondrial DNA-depleted cells against cell death: role of mitochondrial superoxide dismutase. J Biol Chem 2004;279:7512-20

Park SY, Ryu J, Lee W. O-GIcNAc modification on IRS-1 and Akt2 by PUGNAc inhibits their phosphorylation and induces insulin resistance in rat primary adipocytes. Exp Mol Med 2005;37:220-9
Pillay V, Martinus RD, Hill JS, Phillips DR. Upregulation of $P$-glycoprotein in rat hepatoma rho (o) cells: implications for drug-DNA interactions. J Cell Biochem 1998;69:463-9

Polyak K, Li Y, Zhu H, Lengauer C, Willson JK, Markowitz SD, Trush MA, Kinzler KW, Vogelstein B. Somatic mutations of the mitochondrial genome in human colorectal tumours. Nat Genet 1998;20:291-3

Prokipcak RD, Raouf A, Lee C. The AU-rich 3' untranslated region of human MDR1 mRNA is an inefficient mRNA destabilizer. Biochem Biophys Res Commun 1999;261: 627-34

Shay JW, Werbin H. Are mitochondrial DNA mutations involved in the carcinogenic process? Mutat Res 1987; 186:149-60

Wilusz CJ, Wormington M, Peltz SW. The cap-to-tail guide to mRNA turnover. Nat Rev Mol Cell Biol 2001;2:237-46

Wu H, Hait WN, Yang JM. Small interfering RNA-induced suppression of MDR1 (P-glycoprotein) restores sensitivity to multidrug-resistant cancer cells. Cancer Res 2003;63: 1515-9

Yague E, Armesilla AL, Harrison G, Elliott J, Sardini A, Higgins CF, Raguz S. P-glycoprotein (MDR1) expression in leukemic cells is regulated at two distinct steps, mRNA stabilization and translational initiation. J Biol Chem 2003;278:10344-52

Yeh JJ, Lunetta KL, van Orsouw NJ, Moore FD Jr, Mutter GL, Vijg J, Dahia PL, Eng C. Somatic mitochondrial DNA (mtDNA) mutations in papillary thyroid carcinomas and differential mtDNA sequence variants in cases with thyroid tumours. Oncogene 2000;19:2060-6

Zylber E, Vesco C, Penman S. Selective inhibition of the synthesis of mitochondria-associated RNA by ethidium bromide. J Mol Biol 1969;44:195-204 